\title{
Pensar o corpo oprimido d'A Gorda, de Isabela Figueiredo*
}

\begin{abstract}
Resumo
Neste artigo, eu proponho uma tradução do romance $A$ gorda, escrito por Isabela Figueiredo. Se a literatura não é um lugar essencialmente de emancipação, esforço-me em traduzi-lo, enquanto prática política de leitura, a partir da noção de gênero, segundo teorias que diagnosticam e problematizam a condição do corpo da mulher como objeto de discursos e práticas de opressão. Para tanto, parto da hipótese de que a forma como o romance de Isabela foi escrito aproxima-o da noção de "escrita de si". Dessa maneira, o romance se torna a expressão de um corpo falante, que se contrapóe à noção do sujeito Mulher.
\end{abstract}

Palavras-chave: Corpo, Gorda, Gênero, Escrita de si.

\footnotetext{
* Recebido em 03 de janeiro de 2020, aceito em 06 de agosto de 2020.

** Pesquisador do Departamento de Letras Clássicas e Vernáculas da Universidade de São Paulo (USP). São Paulo, SP, Brasil. fabruz@gmail.com / https://orcid.org/0000-0002-0042-8651
} 
Considering The Oppressed Body in Isabela Figueiredo's A Gorda

\begin{abstract}
In this paper, I propose a translation of Isabela Figueiredo's novel A gorda. If literature is not essentially a place of emancipation, I strive to translate it, as a political practice of reading, from the notion of gender, according to theories that diagnose and problematize the condition of women's bodies as objects of oppressive discourses and practices. Therefore, I begin with the hypothesis that the way Isabela's novel was written approximates it to the notion of "self-writing". In this way, the novel becomes the expression of a speaking body, which contrasts with the notion of the woman as subject.
\end{abstract}

Keywords: Body, Fat, Gender, Self-Writing. 


\section{Considerações iniciais: meu lugar de fala}

Este artigo é escrito por um homem: essa é a minha posição dentro das mecânicas da identidade de gênero. Parece-me importante fazer essa declaração no preâmbulo de meu discurso acadêmico a fim de impedir que nele se instale o "Sujeito", ente pretensamente universal,

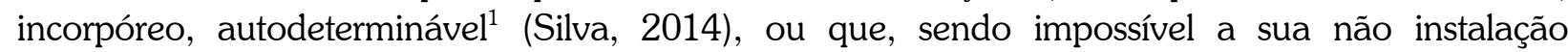
(Lauretis, 1994), ao menos, que lhe fiquem expostos os mecanismos cuja função precípua é, segundo Michel Foucault (2010), a produção da "verdade", de um discurso supostamente higienizado pela "neutralidade" e demais técnicas do saber científico que garantiriam "objetividade" discursiva.

Contra essa mecânica do discurso de poder é que tento me fazer visível, ao responder, a cada verbo aqui escrito, à pergunta velada: quem fala? Afinal, mais à frente, analiso e comento as formas de opressão incidentes em uma mulher - a priori ficcional, personagem do romance $A$ gorda, inventada pela escritora portuguesa Isabela Figueiredo -, e na condição de homem, há categorias naturalizadas em mim que conformam, de maneira bem localizada, sem as perceber, meus modos de ver (ler), pensar, falar (escrever) a respeito do que me caem às mãos, sobretudo, se se trata de alguém ou algo classificado como compósito do sujeito "Mulher" (Beauvoir, 2016) ${ }^{2}$, essa outra forma universal de determinação de um único processo de subjetivação, para o qual não fui educado para a comunidade e contra o qual fui institucionalizado para a prática da violência (Preciado, 2014a). Por esse motivo, neste artigo, minha opção metodológica é a de utilizar verbos conjugados na primeira pessoa do singular, em vez de na terceira pessoa do plural ou na voz passiva, quando há uma escolha a ser feita, por um ou outro rumo interpretativo: a estratégia, então, está em criar orações com sujeitos sintáticos bem à vista, para quebrar o efeito de "neutralidade", ao expor quem diz, sobre quem ou o quê se diz, a partir de quais pressupostos, para quais finalidades.

Nesse mesmo caminho, lembro das ponderações de Grada Kilomba (2019), sobre a ligação entre a forma e o conteúdo de um texto acadêmico, e como a busca pela expressão da universalidade produz um saber científico no qual não se imagina mais questionar os próprios pressupostos (quem escreve, quem define sobre o que se deve escrever, para quem se escreve etc.), $e$ apenas se impõe automaticamente o que se acredita como verdadeiro (o que tem aparência de universal). Portanto, afirmo, neste preâmbulo, que este artigo, sem deixar de ser de crítica literária, é um exercício de crítica de si, um esforço solidário em me problematizar, enquanto homem, em minhas próprias dinâmicas de subjetivação a partir do outro. Por isso, tento expor as estratégias de meu discurso, já que tanto os seus ganhos quanto os seus limites são, em certa medida, a radiografia de seu autor.

\footnotetext{
1 O "Sujeito" é uma categoria filosófica de aparência essencial, que surge no contexto do colonialismo entre os séculos XVI e XVII. Ele é a priori a figura do homem branco europeu em busca da expansão de sua área de domínio e, ademais, da imposição do seu sistema de valores a outros povos. Sua "universalidade" (palavra que traz consigo a ideia de comum) é, assim sendo, um eufemismo do processo de levar, a todos os cantos do planeta, a "razão", entendida enquanto poder que atua externamente, em conjunto com a "mente" autodeterminável do sujeito. Como explica Denise Ferreira da Silva (2014:71), trata-se de uma epistemologia, passível de compreensão da seguinte maneira: "a mente [do homem europeu] sozinha determina (decide, julga, sentencia) as regras e motivações por meio das quais a razão universal governa, respectivamente, os movimentos das coisas e as ações dos seres humanos". Nesse sentido, ele é um ente incorpóreo, porque seu corpo nunca é referenciado segundo alguma marca simbólica, sendo caracterizado apenas pelo exercício da razão (Kilomba, 2019). Por esse motivo, as mulheres são sempre consideradas a partir de seus corpos (peso, altura, mamas, quadris etc.).

2 "Mulher" enquanto sujeito constituído de tal maneira a não ter sentido senão em adjacência ao homem (o Sujeito). Segundo Simone de Beauvoir (2016:12-13), "A humanidade é masculina, e o homem define a mulher não em si, mas relativamente a ele; ela não é considerada um ser autônomo". "A mulher determina-se e diferencia-se em relação ao homem, e não este em relação a ela; a fêmea é o inessencial perante o essencial. O homem é o Sujeito, o Absoluto; ela é o Outro [o objeto]".
} 


\section{Por uma crítica literária que não impeça a subalterna de falar}

Ao me propor a analisar um romance escrito por uma mulher, segundo a hipótese de que, nele, há uma exposição sistemática dos mecanismos de opressão incidentes sobre o corpo lido como feminino por um conjunto de instituições criadas para partilhar pessoas em atividades, tempos e lugares, entendo que seja importante, de início, trazer muito brevemente alguns argumentos que interrompam um processo de leitura de literatura encontrado com frequência no espaço universitário brasileiro, o qual, acredito, tem relação com a produção do Sujeito. Esse processo faz geralmente o leitor pressupor que sempre lhe vai saltar aos olhos uma leitura crítica, porque seria inerente a todo texto literário uma espécie de força de desestabilização do comum. Há, afinal, quem defenda que a literatura carregue consigo uma espécie de capacidade de sempre lançar luz sobre as brechas nos discursos que constituem a realidade numa malha de relações de poder.

Em São Paulo, por exemplo, não são raros relatos de intelectuais sobre a importância do contato, na juventude, com o universo mágico presente nos livros infantis de Monteiro Lobato (Natali, 2013), considerados consensualmente como fundamentais para a construção de um pensamento capaz de subverter o visível, porque educado para o lúdico. Não obstante, Jacques Rancière (2017), ao refazer os cursos da história da literatura no mundo ocidental, demonstra não haver, em tal tipo de escrita, um a priori emancipatório: não há, afinal, provas de tal essência nesses livros, algo que os impeça, inclusive, de serem utilizados como instrumentos de reprodução das relações de poder. Retomando o exemplo acima, para compreender o que diz o filósofo francês, lembro que, há menos de dez anos, uma queixa foi apresentada ao Conselho Nacional de Educação, para que essa instituição se manifestasse sobre a possibilidade de retirar do currículo escolar público um livro de Lobato que traz dentro de si passagens de racismo ${ }^{3}$. Eis uma constatação que me parece grave, por tratar-se de escritor cujo trabalho compõe o processo pedagógico de formação do imaginário de um país onde a escravidão dos povos negros se manteve legal por três de seus cinco séculos de colônia e nação, e onde os índices de desigualdade social entre pessoas negras e brancas permanecem alarmantes (Nações Unidas Brasil, 2017). Uma parte da crítica literária aponta, então, para uma espécie de aporia no centro da tese comum de que a literatura teria a função precípua de transformar a sociedade em direção ao "bem", em nada colaborando, por conseguinte, para a manutenção do status quo. Pois, como provoca José Saramago (2010), se o mundo ocidental, há séculos, lê Homero, Cervantes, Dante, Shakespeare, Goethe, Dostoievski, como ele foi capaz de criar coisas que os defensores da essência emancipatória da literatura facilmente classificariam como "mal", feito o tribunal da santa inquisição, as guerras de proporções continentais, os sistemas de colonização, a exploração capitalista?

Para Marcos Natali (2013), leitor de Jacques Derrida, a literatura pode ser tanto subversiva quanto conservadora, uma vez ela não oferecer, por si só, respostas a seus leitores. Ou seja, o processo de interpretação de um romance ou de um poema está, evidentemente, relacionado a seus mecanismos estéticos e retóricos, mas eles não são suficientes para garantir uma única forma de leitura: quem lê assim o faz conforme a própria experiência como leitor, ou seja, não é mero exercício passivo de absorção, mas também sobrecodificação (Barthes, 2012). Essa experiência, porém, nunca se deu com grande liberdade. Pelo contrário, a teoria e a história demonstram ter sido ela sempre tratada como um objeto de disputa: em Platão e Aristóteles, aponta Rancière (2017), já são encontradas receitas de como controlar os significados da palavra escrita. Sob a justificativa de preservar a constituição harmônica da pólis, os filósofos da antiguidade defenderam que cada parte da comunidade deveria ter acesso apenas ao gênero poético hierarquicamente

\footnotetext{
3 O livro em questão é Caçadas de Pedrinho. Um dos trechos seria este: "Tia Nastácia (...) trepou que nem uma macaca de carvão pelo mastro de São Pedro acima, com tal agilidade que parecia nunca ter feito outra coisa na vida senão trepar em mastros" (Lobato apud Natali, 2013). Para expor o problema do racismo na obra de Lobato, Natali recupera cartas escritas pelo autor, numa das quais, por exemplo, ele descreve a literatura como um "processo indireto de fazer eugenia" (Lobato apud Natali, 2013). Para uma análise aprofundada sobre o caso, consultar o artigo de Marcos Natali, indicado na bibliografia.
} 
condizente, ou seja, aos textos para os quais era educado a saber descodificar o significado oficial, por meio de regras de identificação e de interpretação de signos que foram criadas para produzir, naquele que lê, determinados sentimentos e pensamentos que levassem à prática de determinadas ações. Isso porque o controle das expressões poéticas fazia parte do projeto de uma cidade (pólis) de dinâmica equilibrada nas almas, na comunidade e nos poderes que as geriam, de maneira que havia os gêneros de escrita destinados, grosso modo, aos de "alma superior" (epopeia, tragédia) e aos de "alma inferior" (comédia). Segundo Rancière (2017), esse modo de saber predomina no ocidente até o final do século XVIII, quando vozes antes silenciadas passam a compor as grandes narrativas e a descrever os próprios espaços, de modo a tornar visíveis as formas de existência excluídas da vida pública. Aqueles que estavam imprevistos na dinâmica da constituição da subjetividade passam a disputar esse espaço, para criarem suas próprias identidades, suas próprias histórias (Kilomba, 2019). Vozes como a de Virginia Woolf (2018) passaram a ser reconhecidas enquanto lógos, não mais como meros ruídos (phoné) proferidos por animais, já que, até então, "a literatura era um cavalheiro idoso de traje cinza falando sobre duquesas". Entretanto, o poder e suas instituições atualizam-se constantemente, e as maneiras como são interpretados os textos de literatura continuam a ser objeto de manipulação conservadora até o nosso século.

Por isso, é importante trazer a denúncia de Natali (2013) no caso de Lobato: porquanto, no Brasil, em vez de a questão sobre o racismo, na referida obra, gerar um debate amplo sobre o papel da literatura como instrumento de formação de seus cidadãos, ela tem resultado na movimentação de diversas instituições em defesa do consenso ${ }^{4}$ sobre a presença de Lobato nas escolas, por meio de uma articulação refinada de argumentos, não obstante contraditórios, que ora condenam a instrumentalização da leitura de literatura (associações de pesquisadores, críticos e professores afirmando que não caberia uma intervenção do Estado no modo como as crianças devem ler, mesmo que a sugestão seja crítica, os trechos racistas na obra de Lobato), ora defendem o uso da literatura como instrumento pedagógico (Lobato como leitura necessária para o desenvolvimento do pensamento crítico nas crianças). Há, portanto, um saber literário que movimenta os e é movimentado pelos aparelhos de poder e que dissemina, por meio de suas ficções, códigos de constituição da realidade dentro da perspectiva do Sujeito universal. Estética e política compartilham o mesmo berço, lembra Rancière, quando retoma o legado de Platão e Aristóteles: desde a antiguidade, as práticas artísticas (poesia, pintura, teatro etc.) nos ensinam maneiras de ver (visível e invisível), de sentir e fazer, e essas maneiras intervêm nas formas de ser; e a política, por sua vez, ocupa-se do que se vê e do que se pode dizer sobre o que é visto, de quem tem competência para ver e qualidade para dizer (Rancière, 2014b; Kilomba, 2019). Mas Rancière oferece uma alternativa para pensar a literatura fora dessa perspectiva essencialista que, de fato, esteriliza o debate nos estudos literários.

\section{A "escrita de si" como instrumento de crítica literária}

Rancière fala em uma constante busca por declarar a igualdade das vozes, de todos poderem falar sobre tudo, à contramão do especialismo. É contra a lógica da desigualdade, que dá direito apenas ao Sujeito (universal, abstrato, incorpóreo) falar, que o filósofo propõe o exercício de demonstrar a declaração da igualdade de todos falarem sobre qualquer assunto. Esse exercício visa romper os consensos, entendidos aqui como discursos que, de fato, são as vontades da minoria ${ }^{5}$ representada pelo mercado financeiro (parametrizadas no homem branco, cis-heteronormativo, do hemisfério norte), e criar espaços para a realização dos dissensos, que, para o filósofo, são a própria política.

\footnotetext{
4 Uso a noção de "consenso" elaborada por Rancière (2014a): o consenso, ao invés de ser o produto bem-acabado da ordenação do caos das discordâncias em uma comunidade, é a impossibilidade de discordar dos próprios dados que resumem o que está sendo discutido; é a própria supressão da cena política do exercício do dissenso. No consenso, está pressuposto o portador do lógos, aquele que é capaz de reproduzir a ordem do discurso, e contra essa ordem, não há contestação, porque, contrariamente, não há palavras, apenas phoné.

5 A título de esclarecimento, utilizo a noção de "minoria" que Rancière emprega em sua discussão sobre a democracia: ou seja, "minoria" quantitativa.
} 
Dentro dessa lógica, então, é que tento construir este artigo, tomando o romance de Isabela Figueiredo como um relato de uma mulher gorda ${ }^{6}$. Acredito que, dessa maneira, eu possa, de certa maneira, desarticular alguns argumentos da "ordem do discurso" do poder (Foucault, 2009) e aderir ao movimento que Gayatri Spivak (2014) propõe após diagnosticar que, no mundo da internacionalização do pensamento ocidental, a "subalterna" é impedida de falar: é fundamental a criação de mecanismos que tornem audível a voz de quem é silenciada, que tornem visível quem é considerada sem qualquer valor estético, político, ético para compor a história. Spivak (2014:79) nos adverte dos riscos dessa missão, que, a priori, deveriam ser evitados, para não excluir pela subjugação, "qualquer forma de análise [do sujeito subalternizado], quer seja psicológica, psicanalítica ou linguística". Por isso, afirmo que, metodologicamente, o que tento realizar aqui enquadra-se numa espécie de "tradução" do romance de Figueiredo, um trabalho de expor, por meio da discussão do texto literário, uma voz que, para ser ouvida, prescinde de maior negociação com o que está, como dito, na ordem desse discurso que constitui o imaginário social. Minha tradução é uma tentativa de "operação política de leitura" (Bourcier, 2015:12) do livro de Figueiredo, porque, ciente da inexistência de um conteúdo essencial em suas linhas, de significados imutáveis em suas palavras à espera de decifração, entendo ser importante praticar uma crítica literária desviante do consenso, que colabore, por conseguinte, para a circulação da fala de uma mulher que relata a dor de ter um corpo gordo, considerado "inadequado", segundo as regras naturalizadas de beleza ocidentais. Pois também estou ciente de que essas mesmas palavras literárias podem ser transformadas em outra coisa, algo mais próximo do silenciamento.

A "escrita de si", conceito desenvolvido por Foucault (2004), é, então, uma ferramenta que me ajuda a viabilizar tal tradução: ler o romance de Figueiredo como "exercício pessoal feito por si e para si", mas aberto a um outro leitor como espaço intersubjetivo em que se busca a constituição de subjetividades éticas e políticas e a transformação social a partir da narrativa ou descrição das próprias experiências. Nos termos de Margareth Rago (2011), um exercício, pela palavra, em "construir um estilo de existência, assegurando o testemunho pela própria vida". Proponho, portanto, a leitura d' $A$ gorda como relato autobiográfico de Figueiredo, sem, contudo, deter-me em um mapeamento dos fatos a fim de separar realidade (enquanto verdade) de ficção (enquanto mentira), pois, como argumenta Rancière (2017), eis uma distinção muitas vezes utilizada apenas para reduzir a significância de um modelo de racionalidade (a ficção) criado, desde Aristóteles, para tornar perceptíveis ou inteligíveis as coisas, as situações e os acontecimentos. Não obstante, não deixo de me valer dos tantos pontos de contato da história da personagem Maria Luísa e de sua autora, que reforçam, aqui, o uso de uma perspectiva de leitura a partir do gênero literário da autobiografia: ambas nasceram em Lourenço Marques, capital da Moçambique do período da colonização portuguesa; ambas tiveram de se mudar, muito jovens, para Lisboa, diante da luta popular pela independência do país africano; ambas passaram grande parte da vida sob a alcunha de "gorda"; ambas se submeteram ao procedimento da gastrectomia, e, mesmo emagrecendo, continuaram a se autodefinirem como gordas (Salles, 2018:153) etc.

"Escrever é (...) 'se mostrar', se expor, fazer aparecer seu próprio rosto perto do outro", afirma Foucault (2004:156). Por isso, tal romance, como "escrita de si", enriquece o processo de sua tradução, à medida que me permite afastar a perspectiva da confissão (categoria religiosa que pressupõe que se fala para expor os pecados, à espera de um julgamento e uma punição de quem ouve), e fazer uso da ideia de desconstrução de narrativas que tentam controlar as vidas das mulheres (cito novamente a frase de Woolf: "a literatura era um cavalheiro idoso de traje cinza falando sobre duquesas"), a fim de produzir novas cartografias de existência (Rago, 2011). Leio a seguir, então, a escrita de si n' $A$ gorda, para ler a escrita de uma mulher que, ao narrar a própria história, oferece a quem a lê a verdade de quem conseguiu constituir a sua subjetividade de maneira imprevista à ordem do discurso masculino de subjugação do corpo feminino, já que elegeu para si um modo "anormal" de existência: o de ser gorda.

\footnotetext{
6 A personagem/autora deve ser considerada ainda a partir de outras características: é branca, cis-heteronormativa, europeia. Embora importantes, essas características são abordadas de maneira muito superficial, em razão dos limites formais deste artigo.
} 


\section{A "escrita de si" como instrumento de crítica literária O corpo d' $A$ Gorda}

A gorda é um romance narrado na primeira pessoa do singular; quem fala é Maria Luísa - ou Figueiredo -, que inicia o livro com a assertiva: "Quarenta quilos é muito peso". O número é também "corpo", e não apenas a quantidade de "peso" perdida após a gastrectomia (procedimento cirúrgico de redução de estômago). Ela mesma faz questão de especificar o vocábulo: os tais quarenta "era[m] um segundo corpo que transportava comigo" (Figueiredo, 2017:19). Não houve mera perda de peso, portanto: a perda foi sobretudo de um corpo adjacente, que permanece apenas na memória. Essa especificidade do vocábulo nos diz algo sobre a maneira como Maria Luísa se vê nessa relação de (re)constituição de si a partir do procedimento cirúrgico: não se tratou somente de intervenção no organismo biológico, porque a intervenção também acarretou alterações na forma de reconhecer-se a si mesma. Nesse início de livro, ela descreve, por um lado, as transformações advindas da gastrectomia: a redução da alimentação a líquidos (caldos, sucos, vitaminas), a constatação do aumento da capacidade em desempenhar atividades físicas antes limitadas pelo sobrepeso etc. Por outro lado, observa que há aspectos de sua vida que resistem à cirurgia: "Serei sempre uma gorda. Sei que o mundo das pessoas normais não é para mim. Continuo a ter o defeito, mas não se vê tanto; tornou-se menos grave. (...) Os aleijados são, como se diz dos diamantes, eternos" (Figueiredo, 2017:20). Ou seja, Maria Luísa não fetichiza a nova condição: ela sabe que não passou a ser "outra pessoa" (hipérbole comumente utilizada para enfatizar uma mudança perceptível), como se imagina que lhe foram os "quarenta quilos" a menos. Não: ela reconhece permanecer à periferia do "mundo das pessoas normais". Porém, sabe não ser mais a mesma de antes: agora, o "defeito" "não se vê tanto", está "menos grave", pois permanece na subjetividade, na maneira como vê, pensa e age sobre o mundo. A personagem precisará lidar, doravante, com o descompasso entre esse seu autorreconhecimento e a nova leitura que as pessoas ao seu redor lhe fazem, sob a nova estética corporal. E, nesse ponto, a questão da sexualidade e do gênero, como tecnologias (Lauretis, 1994; Preciado, 2014b) de constituição da subjetividade, parece-me instrumento adequado para compreender os dilemas sofridos por Maria Luísa - ou, como dito, por Figueiredo.

Esse descompasso entre o reconhecimento de si e aquele que surge a partir do outro fica mais evidente conforme a leitura avança. Um pouco mais à frente no romance, a personagem faz uma breve descrição do que se tornou o exercício de contrapor o passado e o presente de seu corpo, ao olhar para as roupas penduradas em seu armário. Maria Luísa admite: "Custa enfrentar o tamanho das roupas. Não quero visualizar-me metida dentro de panos que me transportam a muitos quilos $e$ dores atrás, nem voltar a parecer uma mulher que não se consegue olhar ao espelho", todavia, ela enfatiza não ser "capaz de deitar fora a roupa que me vestiu, que se encostou sem vergonha ao meu corpo doce e mal tocado" (Figueiredo, 2017:22). A grande carga emocional que caracteriza o trecho só pôde ser expressa pelo uso de alguns procedimentos gramaticais e retóricos. O primeiro deles está na aproximação semântica entre "quilos" e "dores": efeito causado pelo uso do mesmo adjetivo "muitos" para ambos os substantivos, não obstante, em termos de concordância nominal, "dores" conter designativo feminino. O segundo está no uso de prosopopeia em "roupa", reforçado pela construção em voz passiva das orações do contexto, pois é "roupa" o sujeito sintático dos verbos em "me vestiu" e "encostou sem vergonha". O terceiro, por fim, está na caracterização do "corpo" pelos adjetivos "doce", sinônimo de "dócil", e "mal tocado", sinônimo de "pouco estimulado": ou seja, um corpo passivo, carente de contato humano. Ora, o uso desses procedimentos, que atribuem ações e qualidades humanas a coisas inanimadas e torna a personagem objeto passivo de ações externas a ela, expõe, enquanto escolhas da escritora, a intenção em construir a imagem de certa fragilidade de um sujeito (filosófico) que não se reconhece mais a partir dos elementos (roupas) que ajudavam a compor a sua identidade, mas não consegue se desvencilhar deles, porque se sente exposto demais sem eles. "Tenho dificuldade em desfazer-me do que viveu na minha companhia, e a minha roupa de gorda foi paciente companheira $e$ testemunha de sentimentos e gestos, de sucessos e fracassos" (Figueiredo, 2017:22-23). Mais uma vez, os mesmos procedimentos são utilizados para reforçar metaforicamente o processo de transformação desse sujeito que parece a priori não estar interessado em se aprofundar nas razões que o levaram a se submeter à gastrectomia. 
A descrição, contudo, faz parte do processo de um novo reconhecimento de si. Maria Luísa precisa falar de si a fim de reconhecer as próprias transformações e, a partir daí, aprender, consigo mesma, sobre elas. Não localizei registros linguísticos de uma narradora que fala de si em busca de um julgamento do leitor e, por isso, como quem divide uma experiência que pode ser útil a quem a ouve, Figueiredo me parece fornecer, neste momento, dois pontos de partida para pensarmos os motivos que levaram à gastrectomia: "Nunca terei um corpo como o da Tony, suficientemente esbelto para agradar ao David" (Figueiredo, 2017:23). O primeiro ponto está em Tony, amiga do tempo de colégio; e o segundo em David, o homem que encarna a figura do amor: e em ambos, a questão do corpo é central na compreensão da dinâmica de subjetividade de Maria Luísa, de si consigo mesma e com a figura do outro. Todavia, diante das limitações de extensão deste artigo, opto por abordar apenas o primeiro ponto, o qual, acredito, dá conta de fornecer elementos para a análise que aqui proponho ${ }^{7}$. Pois, na relação de Maria Luísa com Tony, encontro o problema da constituição da identidade feminina por meio do paradigma do corpo feminino ideal: Maria Luísa compara o seu ao da amiga, considerada, nos anos do colégio, um símbolo de desejo pelos garotos e de beleza pelas garotas. Nesse recorte da narrativa, a personagem principal nos conta sobre as situações às quais o seu corpo esteve exposto, em meio a disputas de interesses diversos aos seus, como se fosse o objeto de negociações entre agentes externos a si que, para vencer, precisavam convencê-la a aderir a normas de controle de seus desejos. Se é possível compreender esses agentes como metáforas que figuram algum processo de psicose ou outro transtorno psíquico que impusesse o signo da loucura à personagem, parece-me, entretanto, mais acertado compreendê-los enquanto maneiras de representar processos históricos que sistematicamente oprimiram, e oprimem, todas as pessoas categorizadas no sujeito Mulher, para que seus corpos funcionassem conforme determinados parâmetros biológicos, éticos, econômicos, jurídicos, estéticos e políticos. Por isso, faço uma breve digressão histórico-filosófica, para apresentar e explicar minimamente essa forma de opressão que, ao longo do romance, parece-me se tornar mais evidente em suas operações sobre o corpo de Maria Luísa.

\section{Sobre os mecanismos de opressão ao corpo feminino}

No mundo ocidental, o corpo da mulher ${ }^{8}$ é objeto de dominação pelo Estado e por suas instituições. Da forma como a conhecemos, essa dominação nasce no que pode ser considerada, segundo Silvia Federici (2019), a primeira grande crise populacional de nível internacional, que assolou as colônias americanas e a Europa nos séculos XVI e XVII. Até então, os governantes não se preocupavam em controlar o crescimento da camada social de seus subordinados; contudo, diante do grande número de mortes nas américas, resultado das práticas violentas de colonização sobre os povos nativos, e do baixo número de nascimentos numa Europa em que as pessoas, independentemente da classe social, demoravam cada vez mais a casar, e em que os pobres (classe trabalhadora) eram relutantes em se reproduzir, nesse contexto, surgiu a preocupação com a falta de mão de obra para continuar a fazer progredir o processo de acumulação de riquezas (a propósito, esse era o momento em que o capitalismo começava a surgir, como resposta ao declínio do sistema feudal).

O que Federici (2019) acentua, por meio dos resultados de sua pesquisa, é que, dentro de um contexto de crise populacional e econômica, de proporção internacional, o corpo da mulher foi transformado em objeto de controle institucional, visto que uma das medidas fundamentais para a

\footnotetext{
7 A título de informação, diz a personagem sobre sua relação com David: "O nosso namoro foi piorando desde que me proibiu de o visitar. (...) Só namoradas que os amigos aprovassem e lhe garantissem um lugar no Olimpo da fama de macho. (...) O David não sabia que a sua vergonha não implicava apenas a sua rejeição, mas a de toda a cultura, que nos envolvia através dele. (...) Olhar o David evocava a minha impossibilidade de inclusão no mundo feminino. Eu não era uma mulher, mas uma massa disforme de carne sem valor" (Figueiredo, 2017:225-226).

8 Importante frisar que Federici se refere, especificamente, ao corpo da mulher europeia (branca). Não obstante, a filósofa observa: "a condição da mulher negra revela de uma forma mais explícita a verdade e a lógica da acumulação capitalista. Mas, apesar das diferenças, em ambos os casos o corpo feminino foi transformado em instrumento para a reprodução do trabalho e para a expansão da força de trabalho, tratado como uma máquina natural de criação, funcionando de acordo com ritmos que estavam fora do controle das mulheres" (Federici, 2019:178).
} 
solução dessa crise foi controlar o crescimento populacional (não à toa, para a lógica mercantilista, grandes populações eram sinônimo de riqueza), e, para tanto, fez-se imprescindível regular a reprodução humana, até então sob "controle das mulheres" (Federici, 2019:170). Começaram a surgir, em função desse objetivo, os códigos legais europeus que penalizavam, com a morte, as mulheres consideradas culpadas por crimes reprodutivos (contracepção, aborto, infanticídio); surgiram também discursos de valorização do casamento e da sexualidade, proferidos pelas novas modalidades religiosas nascidas a partir da Reforma protestante; criaram-se as políticas de "caça às bruxas" (perseguição às mulheres que portavam saberes de controle de natalidade e de sexualidade não reprodutiva); desenvolveram-se formas de vigilância para assegurar que as mulheres não interromperiam a gravidez (o que previu a marginalização da figura da parteira para o surgimento da figura do médico); dentre outras medidas. "O resultado destas políticas, que duraram duzentos anos (...), foi [então] a escravização das mulheres à procriação" (Federici, 2019:178). Para garantir a efetividade desse papel social, ainda, contra as mulheres, práticas de desvalorização de seus trabalhos foram implantadas, e dessa maneira, criava-se a relação de sujeição delas para com os homens. Essas são, então, as bases para a construção de uma identidade feminina centrada na reprodução e no trabalho não remunerado, circunscrito ao âmbito privado (doméstico) (Federici, 2019): esse é, portanto, o nascimento do modelo de controle institucional moderno ${ }^{9}$, de vida e de morte, do homem sobre a mulher.

A esse respeito, Paul B. Preciado (2014a) oferece uma perspectiva adjacente e complementar a de Federici: ao recuperar a análise de Foucault (2009) sobre a figura do soberano, o filósofo afirma que essa forma de poder, que se estendeu até o século XVIII, e que se expressava como o poder de dar a morte, em verdade, ele encarnava não somente na figura do rei, mas, sobretudo, representava o corpo do homem. Preciado fala de uma forma de governo pensada para monopolizar ao homem as técnicas de morte, na construção de uma ideia de masculinidade fundamentada em técnicas de violência. Por isso, no patriarcado, pai (pater) é quem tem o direito de tirar a vida a quem lhe está sujeito, ou seja, os filhos e, notadamente, a mulher. "O que define a masculinidade, que inventa a modernidade ocidental, é os usos e o monopólio das técnicas de violência" (Preciado, 2014a).

No cerne do processo da constituição da subjetividade moderna, portanto, segundo Preciado, está uma epistemologia do corpo masculino que não reconhece no corpo feminino um sujeito, por tratar-se de uma espécie de anomalia do corpo masculino: há apenas o pênis, e a vagina é um pênis invertido, nos termos do saber médico de então. "A mulher era pensada (...) como um corpo subalterno, uma deformação da anatomia masculina" (Preciado, 2014a). Identificar-se como mulher era identificar-se numa patologia, e, sendo assim, aceitar tornar-se objeto de conhecimento médico-jurídico, para a aplicação de práticas e discursos institucionais economicamente mais eficazes para controle da população. Patologias, doenças, epidemias, são todos nomes (re)criados para demarcar um assunto de Estado, uma crise que a priori põe em risco a população ${ }^{10}$. Por isso, no corpo da mulher, desde o século XVIII, são pré-inscritas medidas de controle, haja vista a justificativa do perigo da eclosão de uma crise. E nesse sentido, ao retomar Federici, fica claro que as políticas e leis de controle de natalidade enquadram-se nessa epistemologia do controle do corpo feminino, já que o monopólio da violência está "naturalmente" sob mãos masculinas.

\footnotetext{
9 Segundo Federici (2019:192), "na Europa pré-capitalista, a subordinação das mulheres aos homens esteve atenuada pelo fato de que elas tinham acesso às terras e a outros bens comuns, enquanto no novo regime capitalista as próprias mulheres se tornaram bens comuns, dado que seu trabalho foi definido como um recurso natural que estava fora da esfera das relações de mercado".

${ }^{10}$ População é "uma das grandes novidades nas técnicas de poder, no século XVIII, foi o surgimento da 'população', como problema econômico e político (...). Os governos percebem que não têm que lidar simplesmente com sujeitos, nem mesmo com um 'povo', porém com uma 'população', com seus fenômenos específicos de vida, fecundidade, estado de saúde, incidência das doenças, forma de alimentação e habitaf' (Foucault, 2009:31). Para garantir a "progressão natural da propagação" da população, são necessários, então, corpos femininos aptos à reprodução e a trabalhos sob supervisão do varão.
} 


\section{Pensar o corpo d'A Gorda}

Ora, se o corpo feminino é historicamente objeto de tecnologias institucionais, oprimido para que esteja constantemente apto a atender às diretrizes de controle reprodutivo da população, que visam o progresso do capitalismo e a manutenção do Estado; e se tomar conhecimento da existência de toda essa estrutura implica na visibilidade de mecanismos de constituição de subjetividades, não só femininas, também masculinas, adequadas a atenderem a tais interesses; parece-me importante pensar o contexto de Maria Luísa a partir dessa rede de relações de poder, no momento de lhe traduzir os episódios que a levam à gastrectomia. Para tanto, retomo o ponto de partida da narrativa supramencionado, para analisá-lo, agora, sob a perspectiva oferecida pelas teorias.

Como dito, Tony é a amiga de Maria Luísa do tempo de colégio, e a relação entre elas, como tentarei demonstrar, funciona pela comparação entre seus corpos femininos. Uma passagem do livro é reveladora nesse sentido, em que Maria Luísa faz a seguinte afirmação: "Tony era magra, bastante direita, e usava Levis muito justa, torneando a perna fina, a barriga chata e o peito pequeno"; em contrapartida, continua a narradora, "Eu era gorda, com alta miopia, barriga e mamas a sério. Eu era a subalterna. A boa e inteligente serviçal e feia" (Figueiredo, 2017:32). É notável como Figueiredo constrói esses dois períodos descritivos de maneira muito paralelística: "magra" x "gorda", "bastante direita" (postura ereta) x "alta miopia" (curvada, como quem tenta se aproximar do objeto para vê-lo), "barriga chata e o peito pequeno" x "barriga e mamas a sério". O efeito da construção dessa comparação é quase como a de um silogismo, cuja lógica nos força a chegar a uma única e irrefutável conclusão: Maria Luísa é naturalmente "subalterna" aquela que não deve (ou não pode?) se pronunciar sobre nada, apesar de "boa e inteligente", qualidades tratadas, aqui, como de menor grandeza face à força derivada da concatenação perfeita dos atributos físicos da amiga. Esse argumento que atribui, dentro dessa relação, valor político a características físicas (a magra bela comanda a gorda feia), encontra seu fundamento no pressuposto social de que toda pessoa gorda é "incapaz" (Vigarello, 2012:332). Logo, há códigos linguísticos e representações culturais em jogo que organizam verticalmente a amizade dessas duas personagens, a partir das características de seus corpos femininos. E lembrando das contribuições teóricas de Federici e Preciado, parece-me construtivo pensar tal relação a partir da ideia de que, de um lado, há uma personagem em cujo corpo são encontrados elementos que despertam o desejo, enquanto, do outro, verifica-se o repúdio. O desejo indica para que lado o poder se direciona, para qual lado vão ser imprimidos os seus efeitos de opressão (do comando "é preciso mudar") $e$ também produção (de como e para o quê se mudar). Pois mesmo tratando-se de duas garotas, é a epistemologia da masculinidade que fornece os termos para a construção dessa relação de comparação, em que uma é tratada como mais (Mulher) que a outra. A propósito, no livro, há uma passagem em que os "rapazes" do colégio confirmam essa hipótese:

[Diz Maria Luísa] Acompanhar a Tony [pelo corredor do colégio] era uma fonte de stress, porque ela atraía os olhares dos rapazes e isso piorava a minha situação. Estando ao seu lado, facilmente veriam a bela $e$, dois passos atrás, o monstro. Os rapazes rodeavam-na. Eu teria preferido ficar escondida. Ela chamava-me, "esta é a minha amiga", apresentava, sentindo-se necessitada de companhia que não a ameaçasse. Eles riam-se, tolerando mas desdenhando, troçando da amiga gorda, nas entrelinhas as conversas e situações, porque Tony era que queriam (Figueiredo, 2017:38).

Conforme Maria Luísa, a comparação entre os tais corpos era inevitável naquele ambiente, pois praticada igualmente por todos. Há um padrão na linguagem utilizada, inclusive, que me leva à conclusão de tratar-se, na cena, da descrição de uma prática sistematizada, não casual, porque evidentemente categoriza e separa, de maneira muito objetiva, a "bela" e o "monstro" como

\footnotetext{
${ }^{11}$ O termo "subalterna", aqui empregado, não segue stricto sensu o conceito defendido por Spivak (2014): em certa medida, Maria Luísa consegue tornar audível a sua voz a seus opressores, diferentemente das viúvas imoladas na Índia. Esta subalternidade da personagem é compreendida, então, como papel hierarquicamente estabelecido de servidão, expresso no culto e cuidado que tem com o corpo de Tony.
} 
identidades, cada qual a receber um tratamento condizente à respectiva natureza (beleza ou monstruosidade). Ora, essa interpretação mostra, na juventude de Maria Luísa, como se pode inscrever, na subjetividade, uma percepção negativa do próprio corpo, que faz nascer o desejo de transformá-lo segundo normas que o adequem aos projetos da comunidade, que exige corpos femininos "belos" e "saudáveis" para a reprodução, ou seja, magros (Vigarello, 2012). E o modelo dessa feminilidade, no romance, eu encontro representado em Tony - daí de aqueles garotos, e até mesmo Maria Luísa ${ }^{12}$, desejarem um relacionamento com ela, e ela mesma, em contrapartida, parecer sentir prazer em ser o objeto de disputa. Está aí a epistemologia masculina posta em seus próprios termos; e Maria Luísa, enquanto representação da inadequação à norma, a sofrer pela opressão, vinda de todos os lados, para deixar de atender aos próprios anseios "monstruosos" e aderir ao "belo". As práticas e os discursos, para tanto, são dos mais cruéis, e todos se sincronizam nessa missão de fazer com que o "monstro" fique exposto, envergonhado de sua "monstruosidade":

\begin{abstract}
Vamos todas para as aulas de saltos altos, envergando a bata em algodão de xadrez vermelho $e$ branco, farda que todas odeiam, e a que chamam pano de cozinha, mas que sinto proteger-me da gordura que se escancarará, caso me vista com roupa de uma rapariga normal. Sobre a bata, um blusão azul da Melka, em caqui grosso, comprado num saldo dos Porfírios na Baixa, em Lisboa, no final do verão anterior. Encontrei-o num monte de roupa de homem, quase tudo em $\mathrm{XL}$, porque os homens têm direito a ser grandes. O corte masculino apresenta o desenho de tiras de tecido amarelo-mostarda e branco-sujo a todo o comprimento debaixo dos braços. Não escolhi a cor nem o modelo. Nada me servia. Escolheu-se sozinho. Eu cabia nele, e assim se tornou o blusão certo (Figueiredo, 2017:38-39).
\end{abstract}

Até mesmo as roupas de Maria Luísa são produzidas de modo a lembrá-la e impor-lhe determinadas regras ao corpo: mulheres não podem ser grandes, esse é um direito exclusivo a homens. Visto que, à mulher, o pouco tecido das roupas expressa alguém que está despreparada (devido à compleição física pequena, frágil) para o trabalho (braçal, que é o paradigma de oposição às delicadezas do doméstico), e restrita à reprodução (a roupa deve expor e esconder partes do corpo que despertem o desejo masculino em realizar o ato sexual de gerar descendentes); ao homem, as roupas grandes são o inverso nessa dicotomia, com muito tecido para proteger um corpo (de compleição física robusta) voltado ao trabalho duro, um trabalho que é também de reprodução (o mais forte, por ser o mais apto, deve ser o mais desejado pela mulher). Como disse Woolf (2018:178): "Meras futilidades, como parecem, as roupas possuem (...) funções mais importantes do que apenas nos manter aquecidos. Alteram nossa forma de ver o mundo e de sermos vistos pelo mundo". E é esse o efeito encontrado em Maria Luísa, ao vestir roupas que não lhe são projetadas ao corpo:

De passagem escuto, "olha a baleia, a baleia azul". Sou eu. Riem. Troçam. Não consigo perceber as frases completas. Recuso ouvir. Bloqueio a audição trespassada por esse nome adjetivado, que ecoa no meu cérebro, no percurso da sala de convívio feminino até à de aulas, e no caminho inverso (...). São apenas rapazes do ciclo, os mais novos. Poderiam ser os outros. Têm a razão. Uma baleia da cor do blusão Melka, que não aquece mas disfarça a barriga. Eles gritam, "vem aí o monstro, o monstro da Arrábida" (...) Está em cena um filme com sucesso, do género do Tubarão, de Spielberg: Orca, a Fúria dos Mares. A orca é maior do que o tubarão, a caminho de baleia, mas mais perigosa, evitável, um tubarão-baleia, fatal, horrendo, a abater sem mercê. Eles riem enquanto caminho, eles falam sozinhos, "ó orca, grande fúria dos mares, já comeste hoje alguém?!" Riem. Divertem-se, pueris e crus. Falam sozinhos. Mas a baleia ouve. Não querendo, as frases ficam inscritas no meu cérebro que as rejeita. A baleia. A orca. $\mathrm{O}$ monstro (Figueiredo, 2017:40-41).

\footnotetext{
${ }^{12}$ Há, dentre outras, uma passagem em que Maria Luísa confessa-se atraída pelo corpo de Tony, que lhe desperta, inclusive, amor: "O [corpo] da Tony era um rebuliço oloroso, comestível, onde em sonhos me cravaria inteira, caso a fusão corpórea existisse. Servia Tony como servimos a quem amamos, por bem, por vontade, sem esforço nem favor" (Figueiredo, 2017:32).
} 
Convocando mais uma vez as palavras de Woolf (2018:179): "as roupas que nos usam, e não nós que as usamos (...), elas moldam nossos corações, nossos cérebros e nossas línguas a seu belprazer". Ora, o blusão Melka, masculino tamanho XL, juntamente ao uniforme escolar, inexistente em tamanho às medidas de Maria Luísa, fazem parte de um conjunto de mecanismos institucionais que expõem todo sujeito que se encontra em desconformidade a essa norma corporal, representada, no caso, em Tony. Tony, inclusive, é, em diversas passagens do livro, associada a elementos positivos da cultura pop e masculinizada, o que lhe imprime na pele ${ }^{13}$ variações imagéticas do desejo, como as motocicletas Honda, Yamaha e Kawasaki, os pilotos de corrida Emerson Fittipaldi e Bjorn Borg, o ator John Travolta no filme Saturday Night Fever etc. (Figueiredo, 2017:34-37). Já a roupa de Maria Luísa a faz ser associada facilmente a um conjunto de signos linguísticos (como visto, ao filme d'A orca) que reforçam a ideia de monstruosidade em seu corpo, e a fazem, por conseguinte, pensar, agir, ver a comunidade de maneira muito distinta à maneira de sua amiga. Maria Luísa vive acuada dentro de si mesma, porque, fora de si, há a comunidade, e toda ela entoa o mesmo discurso de nela reconhecer a essência da anormalidade. Logo, não é de se estranhar que a conduta a priori da personagem, de autorreconhecimento, vai se caracterizar pela procura e identificação da anormalidade em si. Por isso, Maria Luísa tem certeza de ser o seu papel o de servir a Tony: de se "debruçar no tanque do quintal, aos sábados à tarde [dia de descanso das aulas], esfregando as suas [de Tony] meias, soutiãs e cuecas, mesmo as manchadas pelo período, como se lavasse a roupa do meu corpo, mas mais sagrado" (Figueiredo, 2017:32). E, também, esperado de si mesma desejar o corpo de Tony, de querer sentir "a densidade" dos "pomos viçosos e tensos", no "côncavo da mão" (Figueiredo, 2017:41). Afinal, essa é a interpretação possível de si nesse ambiente: a realizada segundo o ideal normativo materializado em Tony.

Maria Luísa só consegue problematizar a própria subjetividade condicionada à subalternização a partir de um episódio que a marca: quando ela ultrapassa os limites simbolicamente estabelecidos nessa relação, e toca acidentalmente as tão almejadas mamas de Tony, enquanto desempenhava outro de seus afazeres subalternos, qual seja, o de passar creme hidratante pelo corpo dessa "realeza" (Figueiredo, 2017:41). São mamas sobre as quais não lhe há o direito de tomar às mãos, logo, em punição, Tony lhe desfere, com um sapato de salto alto, um golpe na cabeça, que lhe abre "um lanho na pele do crânio". Ao sangue jorrar do ferimento, ambas gritam, o que chama a atenção de pessoas do colégio, que entram na sala onde elas estão, para presenciar uma cena que se torna motivo de fofocas. O episódio não resulta no término dessa relação, mas a faz estremecer: "Continuei a lavar e a esfregar a sua roupa [inclusive, as "cuecas" acastanhadas pelo "período"] no tanque do quintal (...), para que ficasse tão branca como a minha cegueira por ela" (Figueiredo, 2017:43). "Cegueira"! Eis o substantivo que me indica a mudança: "cegueira". Na medida em que, usado metaforicamente, ele expressa a problematização que Maria Luísa passa a fazer não apenas de sua relação com Tony: sobretudo, de seu próprio estado de "subalterna". Ou seja, por meio do recurso retórico, Figueiredo constrói um ponto de dualidade interpretativa que me permite ler na fala da personagem principal o seu esforço em atravessar as tantas camadas de códigos de significação negativa de si, para retirar da invisibilidade o seu próprio desejo, as verdades criadas conforme o seu próprio corpo. É verdade que foram precisos anos se passarem, estar fora do colégio, para Maria Luísa conseguir estabelecer o afastamento entre ambas. Tony, inclusive, é quem tenta retomar o contato: queria que a amiga subalterna da juventude fosse a madrinha da filha que estava porvir. Mas a cisão torna-se categórica para a protagonista: "Como é que a Tony não compreendia (...) que tínhamos desenvolvido interesses e vidas completamente

\footnotetext{
${ }^{13}$ Embora não seja um aspecto a ser trabalhado aqui, é importante notar que Tony é descrita como de "pele de rainha africana (...), grossa de angolanos brancos um bocado misturados, ligeiramente parda", além de "longo cabelo ondulado e volumoso, caindo em cachos castanho-escuros" (Figueiredo, 2017:33). Ou seja, uma mulher negra. Tal fato levanta uma questão importante, em face do intransponível tema do racismo contra a mulher negra, no âmbito das memórias coloniais. Como ensina Kilomba (2019:79), a mulher negra é quem tem o corpo erotizado, transformado na "personificação do sexualizado, com um apetite sexual violento". Logo, trata-se este de aspecto complexo dentro do romance de Figueiredo, que mereceria análise. Afinal, é o corpo da mulher negra sendo comparado ao corpo de uma mulher branca, numa perspectiva do desejo sexual do homem branco. E essa problemática, inclusive, merece atenção, pois já é encontrada em seu Caderno de memórias coloniais.
} 
diferentes?! Que estávamos acabadas uma para a outra?!” (Figueiredo, 2017:201). A "sapatada na cabeça" (catacrese de "despertar"), portanto, funciona como um episódio muito representativo no enredo, na medida em que é o registro, no corpo de Maria Luísa, do início da construção dessa "contraconduta" de recusa de viver no binômio "bela" x "monstro", dessa resistência às práticas antigas de docilidade que lhe governaram o corpo na juventude. Paulatinamente, Maria Luísa fortalece em si a percepção de não inerência dessa identidade subalterna, até chegar ao ponto de tornar-se segura em negar o convite de Tony, e enunciar que "estávamos acabadas uma para a outra", frase que, ao mesmo tempo que confirmação a interrupção do domínio do antigo processo de codificação do corpo, reforça a importância de um recomeço dentro de uma outra lógica de constituição de si, a qual não faz Maria Luísa se esquecer de seu passado, mas a permite o traduzir a termos incoerentes à ordem discursiva do poder.

Quando a gastrectomia lhe advém, então, não me parece sustentável ler tal acontecimento cirúrgico dentro de uma perspectiva teleológica, como o resultado esperado para alguém que já se predispunha à "derrota" face à opressão sofrida, em outras palavras, resultado esperado de toda mulher gorda que deseja ter uma aparência de mulher "normal", ou seja, emagrecer. Ora, como tentei demonstrar, Figueiredo nos relata uma história com muitas inflexões complicadas, para mostrar que, depois de viver experiências nada lineares, Maria Luísa se permite fazer uma escolha! A escolha de submeter-se à gastrectomia que, de fato, está ligada à época do colégio com Tony, mas que não é, em si, a mera reprodução da lógica dessa opressão.

\section{Considerações finais}

Há, na verdade, muitos motivos que colaboraram para Maria Luísa se submeter à gastrectomia; de fato, trata-se de um conjunto complexo de fatores. Escolhi analisar, neste artigo, apenas um deles, qual seja, aquele centrado na relação da narradora com Tony. ,Porque esse fator me pareceu dar conta de evidenciar, ao final, que a gastrectomia não deve ser lida como um episódio de resiliência, uma espécie de derrota da personagem face à opressão sofrida; há, no livro, muitos elementos que põem em xeque essa leitura.

A referida contraconduta de Maria Luísa, então, me parece apontar para um processo transformativo no interior da subjetividade da personagem que, mesmo após o procedimento cirúrgico, que lhe dá outra aparência ao corpo, faz questão de se identificar como gorda. Essa leitura que ela faz de si, do próprio corpo, não mais está condicionada aos "quarenta quilos" perdidos. Eis uma explicação para a mudança: o significante do adjetivo "gorda" permanece, mas passa a conter, doravante, outro significado, que aponta para movimentos que têm como objetivo uma outra conduta, qual seja, o desejo de ser conduzida, dentro da malha de relações de poder, de outro modo, para outros fins, por meio de outros procedimentos e de outros métodos, que não os normalmente lidos através dos códigos representados no corpo gordo. Como ensina Marie-Hélène Bourcier (2014:13), leitora de Preciado, o corpo é "espaço de construção biopolítica ${ }^{14}$, como lugar de opressão, mas também como centro de resistência". E é isso o que a personagem d' A gorda me parece mostrar: resistência em manter-se gorda, resistência a se adequar ao mundo das "pessoas normais", como ela mesma afirma em trecho citado neste artigo, mesmo diante das transformações em seu corpo causadas pela cirurgia, a qual escolhera se submeter. Isso porque a sua identidade deixa de depender necessariamente dos mecanismos que conformam o seu desejo a determinados objetivos institucionais e estruturais da comunidade. Ademais, essa configuração do corpo feminino só pode ser abalada, afirma Preciado (2018:29), quando compreendermos que a "identidade sexual não é expressão instintiva da verdade pré-discursiva da carne, e sim um efeito de reinscrição das práticas de gênero no corpo", sendo o gênero "algo que fazemos, não algo que somos (...), uma relação entre nós, não uma essência" (Preciado, 2018:05). Ora, a abordagem a partir da noção de gênero, que permeia toda a análise feita neste artigo, agora fica mais evidente, à demonstração de que ser uma mulher gorda, no romance, é a priori o efeito de um conjunto de discursos e práticas que produzem, a partir do uso de elementos corporais como provas de suas

\footnotetext{
${ }^{14}$ Termo criado por Foucault (2009), não citado diretamente neste artigo. Trata-se de uma forma de poder que tem como alvo as populações. A esse respeito, tratei em nota anterior, sobre a noção de "população".
} 
verdades, a forma como a personagem se identifica, dentro de um parâmetro de anormalidade; e, a posteriori, produto de um desejo de ser alguém que só se descobre através da experiência de si com o outro. Por isso, a relação de Maria Luísa com Tony se me mostrou tão importante para se compreender essa transformação da compreensão de si, da personagem principal, a partir da leitura que ela passa a fazer de seu próprio corpo. Com Tony, Maria Luísa percebe que, a todas as pessoas lidas como Mulher, o mundo da epistemologia do desejo masculino e da reprodução capitalista impõe a elas uma regra condicionante para comporem a sua identidade feminina, que é a do corpo "esbelto", desejável pelo homem, ou seja, um corpo objetificado, que pode propiciar momentos de satisfação àquelas que são cobiçadas, e muita dor às que são vistas, pelos mesmos olhos, como monstros; mas, invariavelmente, em ambos os casos, uma regra que oprime esses corpos a sempre se adequarem a um modelo de existência totalmente alheio ao que eles têm a dizer sobre si mesmos.

Compreender o romance de Isabela Figueiredo enquanto "escrita de si", então, me parece potencializar essa noção de constituição de uma subjetividade imprevista. Pois, repito a frase de Foucault (2004:156), citada na terceira parte deste artigo: "Escrever é (...) 'se mostrar', se expor, fazer aparecer seu próprio rosto perto do outro". E é isso o que Figueiredo me parece cumprir, quando mobilizadas as categorias críticas que aqui as trago. $\mathrm{O}$ romance se constitui em um exercício da sua escritora em conhecer-se por meio da prática de relatar as experiências de sofrer um tipo de violência, que permanece inscrita no corpo, a qual toda mulher gorda é submetida. E nesse sentido, parafraseando Preciado (2014b:29), o romance de Figueiredo "não se dá senão na materialidade dos corpos". Além disso, a linguagem da literatura faz multiplicar os sentidos do livro, tanto mais forem as pessoas a o lerem; e dessa maneira, $A$ gorda se transforma em um ato de generosidade, de abertura para o outro, porque permite que pessoas totalmente alheias à escritora tenham a oportunidade de criar, a partir de suas próprias traduções - dentre as quais, meu artigo se inclui -, formas alternativas de se relacionarem com os seus próprios corpos, ou seja, formas diferentes às dadas de autorreconhecimento e de conhecimento do outro. Acredito que, desnaturalizado o desejo de enquadrar a todos à norma, aceitamos o pressuposto de que cada um tem o direito de escolher a priori as suas ferramentas de enfrentamento ao modo particular de opressão que sofre. E dentro dessa lógica, parece-me haver uma possibilidade de leitura mais complexa para a gastrectomia, tanto de Maria Luísa quanto de Figueiredo, que não seja nem de fracasso, nem de vitória: mas, sim, de resistência.

\section{Referências bibliográficas}

BARTHES, Roland. O rumor da língua. São Paulo, Martins Fontes, 2012.

BEAUVOIR, Simone. O segundo sexo - Fatos e mitos. Rio de Janeiro, Nova Fronteira, 2016.

BOURCIER, Marie-Hélène. Prefácio. In: PRECIADO, Paul B. Manifesto contrassexual. São Paulo, n-1 edições, 2015.

FEDERICI, Silvia. Calibã e a bruxa. São Paulo, Elefante, 2019.

FIGUEIREDO, Isabela. A gorda. Lisboa, Caminho, 2017.

FOUCAULT, Michel. História da sexualidade - A vontade de saber. São Paulo, Graal, 2009.

A escrita de si. In: Ditos \& Escritos. Ética, sexualidade e política. Rio de Janeiro, Forense Universitária, 2004.

KILOMBA, Grada. Memórias da plantação. Rio de Janeiro, Livros Cobogó, 2019.

LAURETIS, Teresa de. A tecnologia do gênero. In: HOLLANDA, Heloísa B. (org.). Tendências e Impasses: o feminismo como crítica da cultura. Rio de Janeiro, Rocco, 1994, pp. 206-241.

NAÇÕES UNIDAS BRASIL. Negros são mais afetados por desigualdades e violência no Brasil, alerta agência da ONU. São Paulo, 2017 [https://nacoesunidas.org/negros-sao-mais-afetados-por-desigualdades-eviolencia-no-brasil-alerta-agencia-da-onu/-acesso em 19 nov 2019]. 
NATALI, Marcos Piason. Questões de herança: do amor à literatura (e ao escravo). In: SANTURBANO, Andrea; MARSAL, Meritxell; PETERLE, Patricia (org.). Fluxos literários: ética e estética. Rio de Janeiro, 7 Letras, 2013, pp.115-132.

PRECIADO, Paul B. Beatriz Preciadoenconversácioncon Marianne Ponsford. Hay Festival Cartagena. 2014a. [https://reddebibliotecas.org.co/diario/beatriz-preciado-y-marianne-ponsford-hay-festival-2014-acesso em 19 nov 2019].

. Manifesto contrassexual. São Paulo, n-1 edições, 2014b.

Transfeminismo. São Paulo, n-1 edições, 2018.

RAGO, Margareth. Escrita de si, parrésia e feminismo. In: VEIGA-NETO, A.; CASTELO BRANCO, G. (org.). Foucault, Filosofia e Política. Belo Horizonte, Autêntica, 2011, pp.251-267.

RANCIÈRE, Jacques. A literatura impensável. In: Políticas da escrita. São Paulo, Editora 34, 2017, pp.27-50. Ainda se pode falar de democracia? Lisboa, KKMY, 2014a.

. A partilha do sensível - Estética e política. São Paulo, Editora 34, 2014 b.

SALLES, Penélope. Entrevista com Isabela Figueiredo. Revista Crioula, n. 22, São Paulo, 2018, pp.146-162 [http://www.revistas.usp.br/crioula/article/view/149973 - acesso em 19 nov 2019].

SARAMAGO, José. Literatura, compromisso e transformação social. Fundação José Saramago, Lisboa, 2010 [https://www.josesaramago.org/sobre-literatura-compromisso-e-transformacao-social/ - acesso em 19 nov 2019].

SILVA, Denise Ferreira da. Ninguém: direito, racionalidade e violência. Revista Meritum, v. 9, n. 1, Belo Horizonte, 2014, pp.67-117.

SPIVAK, Gayatri. Pode o subalterno falar? Belo Horizonte, Ed. UFMG, 2014.

VIGARELLO, George. As metamorfoses do gordo - História da obesidade. Petrópolis, Vozes, 2012.

WOOLF, Virginia. Orlando. São Paulo, Companhia das Letras, 2018.

\section{ERRATA}

No artigo "Pensar o corpo oprimido d'A Gorda, de Isabela Figueiredo", com DOI http://dx.doi.org/10.1590/18094449202100620011, publicado em cadernos pagu (62), 2021:e216211, na página 7,

onde se lia:

"IV. A "escrita de si" como instrumento de crítica literária O corpo d' $A$ Gorda"

leia-se:

"O corpo d'A Gorda" 